\title{
Comparison of Anterior Cerebral Artery Blood Flow Velocity and Cerebral Blood Flow during Hypoxia
}

\author{
ADAM A. ROSENBERG, VINODH NARAYANAN, AND M. DOUGLAS JONES, JR. \\ Department of Pediatrics (Eudowood Neonatal Division), The Johns Hopkins University School of Medicine, \\ Baltimore, Maryland 21205
}

\begin{abstract}
Measurement of anterior cerebral artery blood flow velocity with a continuous wave bidirectional Doppler was compared with cerebral blood flow (CBF) measured with radioactive microspheres in 11 paralyzed newborn lambs during hypoxic hypoxia. The Doppler probe was maintained in a fixed position during each experiment. The objectives of the study were to validate this noninvasive technique that is being used widely in the clinical setting to qualitatively assess changes in $\mathrm{CBF}$, and to evaluate which of the velocity parameters measured provide the most information. Diastolic velocity $(\mathrm{DV})$, peak systolic velocity (PSV), area under the velocity curve (AUC), and pulsatility index (PI) were examined under conditions of varied arterial oxygen content and compared to microsphere CBF. DV ( $r=0.72, p<0.001), A U C(r=$ $0.72, p<0.001$ ), and PSV $(r=0.63, p<0.001)$ demonstrated stronger correlations with changes in CBF than did the PI $(r=-0.41, p<0.05)$. DV $(r=0.81, p<0.001)$, $\operatorname{AUC}(r=0.80, p<0.001)$, and $\operatorname{PSV}(r=0.75, p<0.001)$ also exhibited stronger relationships with changes in arterial oxygen content than did the $P I(r=-0.36, p<0.05)$. These data demonstrate that changes in cerebral blood flow velocity are useful qualitative measures of changes in cerebral blood flow. However, the utility of this technique is dependent upon a stable probe position, and assessment of the actual velocity measurements (DV, PSV, AUC) rather than simply the pulsatility index. (Pediatr Res 19: 67-70, 1985)
\end{abstract}

\section{Abbreviations}

ACA, anterior cerebral artery

AUC, area under the velocity curve

CBF, cerebral blood flow

CBV, cerebral blood flow velocity

CVR, cerebral vascular resistance

DV, diastolic velocity

IVH, intraventricular hemorrhage

PI, pulsatility index

PSV, peak systolic velocity

PVC, polyvinyl chloride

$\mathrm{OD}$, cerebral oxygen delivery

RBC, red blood cells

Received March 12, 1984; accepted July 25, 1984

This work was supported by the Hospital for Consumptives of Maryland (Eudowood).

Correspondence Adam A. Rosenberg, M.D., Department of Pediatrics, Container B-195, University of Colorado Health Sciences Center, 4200 East 9 th Avenue, Denver, CO 80262.
In order to understand more accurately the pathogenesis of intraventricular hemorrhage and hypoxic-ischemic brain injury in the human neonate, there has been considerable interest in non-invasive determinations of CBF. To this end, investigators have used Doppler measurements of blood flow velocity in the $\mathrm{ACA}$ as an indicator of CBF. They have suggested that these measurements have clinical utility for the diagnosis of intraventricular hemorrhage (1) and for the identification of infants at risk for a poor outcome $(2,3)$. Most investigators have used the $\mathrm{PI}=\mathrm{PSV}-\mathrm{DV} / \mathrm{PSV}$, to assess changes in CBF. The PI was introduced by Planiol and Pourcelot (14) to evaluate obstruction in the carotid arteries of adults with peripheral vascular disease. As applied to neonates, the PI is believed to correlate directly with CVR (1). The implication then has been that high resistance is associated with a low CBF and vice versa.

The PI is a ratio of flow velocities and therefore minimizes errors in Doppler probe placement and eliminates the need for velocity signal calibration. However, it has the disadvantage of not being a direct measurement of velocity and equivalent changes in systolic and diastolic velocities can be present without a change in the PI $(8,18)$. Furthermore, studies in similar clinical circumstances have produced conflicting data regarding the PI. Whereas Bada et al. (1) found a high PI with IVH, Perlman and Volpe (13) and Lipman and Brazy (12) did not detect an association between IVH and PI.

It has been suggested $(5,6,17,18)$ that the actual systolic, diastolic, and mean blood flow velocities would be more informative than PI. Batton et al. (4) in newborn puppies and Hansen et al. (8) in piglets have compared Doppler blood flow velocities in the ACA with actual measurements of $\mathrm{CBF}$ during hypercapnia. These groups found significant correlations between $\mathrm{CBF}$ and PSV, DV, the area under the velocity curve, and mean blood flow velocity. In contrast, the PI was not useful. Hansen et al. (8) could find no correlation of CBF with PI and Batton et al. (4) found the unexpected result that PI increased (implying increased resistance) with hypercapnia.

If this noninvasive technique is to be clinically useful, the velocity measurements need to be correlated with $\mathrm{CBF}$ in a variety of circumstances. Therefore we have compared changes in ACA blood flow velocity measured with the Doppler and CBF measured with radioactive microspheres during hypoxic hypoxia in the newborn lamb.

\section{METHODS}

Surgical procedures. Eleven lambs aged 2-7 days were operated upon under pentobarbital anesthesia. PVC catheters $(0.034$ in ID $\times 0.054$ in OD; Martech Medical Products, Lansdale, PA) were placed into the brachiocephalic artery and left ventricle via axillary arteries and into the abdominal aorta via a femoral artery 
as previously described (16). An artificial "fontanelle" was created $(2 \mathrm{~cm}$ in diameter) at the junction of the coronal and sagittal sutures by drilling a burr hole through the calvarium. The dura was left intact.

Measurements. $\mathrm{CBF}$ was measured using the radioactive microsphere technique $(10,16)$. In each animal, CBF was measured during normoxia, moderate hypoxia, and severe hypoxia. Radioactive microspheres (approximately $1.0-1.5 \times 10^{6}$ ) $15 \mu \mathrm{M}$ in diameter labeled with ${ }^{85} \mathrm{Sr},{ }^{95} \mathrm{Nb},{ }^{46} \mathrm{Sc}$, and ${ }^{153} \mathrm{Gd}(3 \mathrm{M}$, St. Paul, MN and New England Nuclear, Newton, MA) were injected into the left ventricle over $1 \mathrm{~min}$ from a continuously stirred mixture containing 300,000 microspheres $/ \mathrm{ml}$. A reference blood sample was withdrawn from the brachiocephalic artery at a rate of 2.54 $\mathrm{ml} \cdot \mathrm{min}^{-1}$ with a pump (Harvard Apparatus, Dover, MA). Withdrawal began $1 \mathrm{~min}$ before the microsphere injection and continued for $1 \mathrm{~min}$ after it was completed. The injections were not associated with changes in heart rate or blood pressure. CBF was calculated according to the following equation:

$$
\dot{\mathrm{Q}} \mathrm{c}=\frac{\mathrm{cpm}_{\mathrm{c}}}{\mathrm{cpm}_{\mathrm{r}}} \times \dot{\mathrm{Qr}}
$$

where $\mathrm{Q} c$ is cerebral blood flow $\left(\mathrm{ml} \cdot 100 \mathrm{~g}^{-1} \cdot \mathrm{min}^{-1}\right) ; \mathrm{cpm}_{\mathrm{c}}$ is counts per minute in the "cerebral" tissue sample (all tissue rostral to the pons); $\mathrm{cpm}_{\mathrm{r}}$ is the counts per minute in the reference blood sample, and Q $r$ is the withdrawal rate of the reference blood sample $\left(\mathrm{ml} \cdot \mathrm{min}^{-1}\right)$. The radioactivity in each sample was determined with a two-channel $\gamma$ counter (Tracor Analytic, Des Plaines, IL). Adequate mixing of microspheres was confirmed by comparison of right and left cerebral hemispheres and multiple brachiocephalic artery reference blood samples. All reference and tissue samples contained greater than 400 microspheres.

Cerebral blood flow velocity measurements were made with a bidirectional continuous wave Doppler with a 2 channel strip recorder (Medasonics, Mountain View, CA). An $8 \mathrm{MHz}$ pencil probe was used. The machine was calibrated prior to each experiment by the technique described by Shoor et al. (19). The signal from each anterior cerebral artery was identified. The probe was positioned to obtain the maximum audible signal and the maximum frequency shift. To minimize contributions to the signal from other vessels, we sought a position in which the same wave pattern was present in both the advancing flow channel and the bidirectional channel. When the position was satisfactory, the position of the probe was fixed with a clamp. We measured PSV, DV, PI, and AUC (Fig. 1). For each determination five cardiac cycles were averaged. We found no difference in the values when we compared 5,10 , or 15 cardiac cycles. AUC measurements were corrected for the number of cardiac cycles per minute.

Blood samples for $\mathrm{pH}$, arterial $\mathrm{CO}_{2}$ tension $\left(\mathrm{PaCO}_{2}\right)$, arterial $\mathrm{O}_{2}$ tension $\left(\mathrm{PAO}_{2}\right)$, arterial $\mathrm{O}_{2}$ content $\left(\mathrm{CAO}_{2}\right)$, and hematocrit were withdrawn anaerobically into heparinized Natelson glass

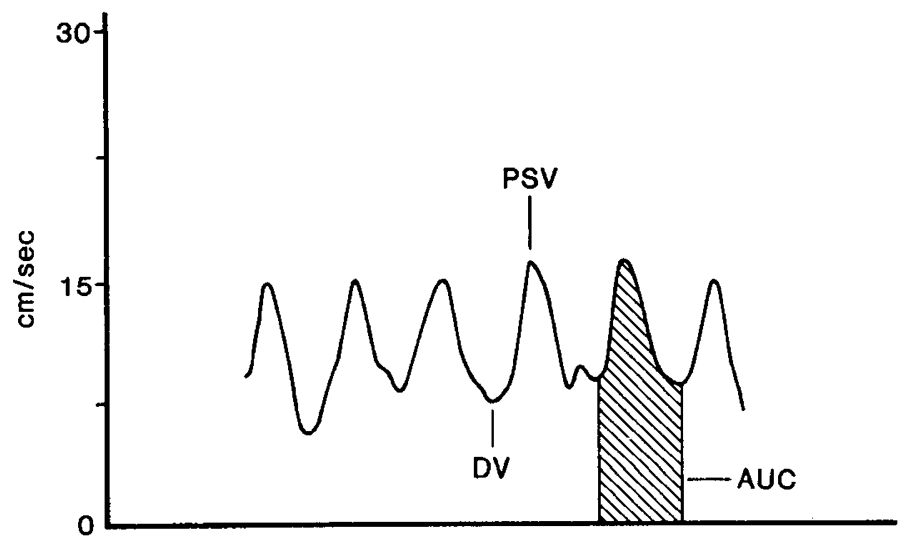

Fig. 1. Representative Doppler tracing from the anterior cerebral artery. pipettes from the brachiocephalic artery. Oxygen contents were measured using the Lex- $\mathrm{O}_{2}$-Con-TL (Lexington Instruments, Waltham, MA). $\mathrm{PAO}_{2}, \mathrm{PACO}_{2}$, and $\mathrm{pH}$ were measured at $39.5^{\circ} \mathrm{C}$ using the Radiometer BMS3 MK2 (Radiometer, Copenhagen). Hematocrit was measured with the microhematocrit technique. Blood pressure and heart rate were continuously monitored in the abdominal aorta (Gould Instruments, Oxnard, CA). Blood pressure was referenced to the right atrium.

Experimental protocol. One hour after completion of the surgical procedure, the pentobarbital sedated animals were paralyzed with pancuronium $(0.1 \mathrm{mg} / \mathrm{kg})$, placed on a ventilator (Bourns, Inc., Riverside, CA) and the Doppler probe positioned. The ventilator rate, tidal volume, and $\mathrm{FIO}_{2}$ were adjusted to the three desired levels of arterial blood gases (control, moderate hypoxia, and severe hypoxia). Cerebral blood flow velocity in the ACA was measured prior to and after the completion of each microsphere injection. Sets of measurements taken at the three levels of arterial blood gases were $30 \mathrm{~min}$ apart. The $\mathrm{PAO}_{2}$ was maintained for $10 \mathrm{~min}$ prior to measuring blood flow velocity and $\mathrm{CBF}$.

Data analysis. The Doppler blood flow velocity determinations (PSV, DV, AUC, and PI) were compared with microsphere measurements of cerebral blood flow using linear regression analysis. The relationships between PSV, DV, AUC, and PI with $\mathrm{CAO}_{2}$ were also examined with linear regression analysis after a linear transformation. Comparisons of arterial blood gases, $\mathrm{CAO}_{2}$, blood pressure, and heart rate among control, moderate, and severe hypoxic groups were done using a paired $t$ test with a Bonferroni correction (22).

\section{RESULTS}

The physiologic variables during control, moderate, and severe hypoxia are presented in the Table 1 . There were no significant differences in $\mathrm{PACO}_{2}$, blood pressure (systolic, diastolic, and mean), and heart rate. Hematocrit did not change significantly during the course of the experiment.

Doppler $C B V$. The relationships of DV (Fig. 2), AUC (Fig. 3), and PSV to changes in $\mathrm{CAO}_{2}$ are described by the following equations: $\mathrm{DV}=54.61 / \mathrm{CAO}_{2}+5.5(\mathrm{r}=0.81 ; p<0.001), \mathrm{AUC}$ $=72471 / \mathrm{CAO}_{2}+862(\mathrm{r}=0.80 ; p<0.001)$, and $\mathrm{PSV}=78.71 /$ $\mathrm{CAO}_{2}+9.5(\mathrm{r}=0.75 ; p<0.001)$. PI $(\mathrm{r}=-0.36 ; p<0.05)$ showed the weakest relationship with changes in $\mathrm{CAO}_{2}$.

Comparison of $C B V$ and $C B F$. Figure 4 depicts the relationship between DV and CBF. It is a linear relationship (slope $=0.06$ $\left.\mathrm{cm} \cdot \mathrm{sec}^{-1} / \mathrm{ml} \cdot 100 \mathrm{~g}^{-1} \cdot \mathrm{min}^{-1} ; \mathrm{r}=0.72 ; p<0.001\right)$. AUC versus CBF (Fig. 5) is also a linear relationship (slope $=7.82$ units. $\left.\mathrm{min}^{-1} / \mathrm{ml} \cdot 100 \mathrm{~g}^{-1} \cdot \mathrm{min}^{-1} ; \mathrm{r}=0.72 ; p<0.001\right)$ as is PSV versus $\mathrm{CBF}$ (slope $=.08 \mathrm{~cm} \cdot \mathrm{s}^{-1} / \mathrm{ml} \cdot 100 \mathrm{~g}^{-1} \cdot \mathrm{min}^{-1} ; \mathrm{r}=0.63 ; p<$ 0.001 ). PI (slope $=-0.38 / \mathrm{ml} \cdot 100 \mathrm{~g}^{-1} \cdot \mathrm{min}^{-1} ; \mathrm{r}=-0.41 ; p<$ 0.05 ) showed the weakest correlation with microsphere CBF.

Table 1. Physiologic measurements*_control, moderate, and severe hypoxia

\begin{tabular}{lccc}
\hline & Control & Moderate & Severe \\
\hline $\mathrm{CAO}_{2}(\mathrm{vol} \mathrm{\%}) \dagger$ & $17.5 \pm 0.6$ & $9.6 \pm 0.5$ & $5.2 \pm 0.3$ \\
$\mathrm{PAO}_{2}(\mathrm{~mm} \mathrm{Hg}) \ddagger$ & $83.1 \pm 7.9$ & $35.5 \pm 8.6$ & $28.0 \pm 2.5$ \\
$\mathrm{PACO}_{2}(\mathrm{~mm} \mathrm{Hg})$ & $36.9 \pm 1.7$ & $35.0 \pm 1.9$ & $34.6 \pm 1.4$ \\
$\mathrm{MAP}(\mathrm{mm} \mathrm{Hg})$ & $80 \pm 2$ & $81 \pm 3$ & $77 \pm 3$ \\
$\mathrm{HR}\left(\mathrm{min}^{-1}\right)$ & $253 \pm 10$ & $293 \pm 12$ & $274 \pm 21$ \\
\hline
\end{tabular}

*All values mean $\pm \mathrm{SEM}$ where $\mathrm{CAO}_{2}=$ arterial oxygen content, $\mathrm{PAO}_{2}$ $=$ arterial oxygen tension, $\mathrm{PACO}_{2}=$ arterial $\mathrm{CO}_{2}$ tension, $\mathrm{MAP}=$ mean arterial blood pressure, and $\mathrm{HR}=$ heart rate.

$\dagger$ Control differs significantly from moderate $(p<0.001)$ and severe $(p<0.001)$. Moderate differs from severe $(p<0.05)$.

$\ddagger$ Control differs significantly from moderate $(p<0.01)$ and severe $(p$ $<0.001)$. 


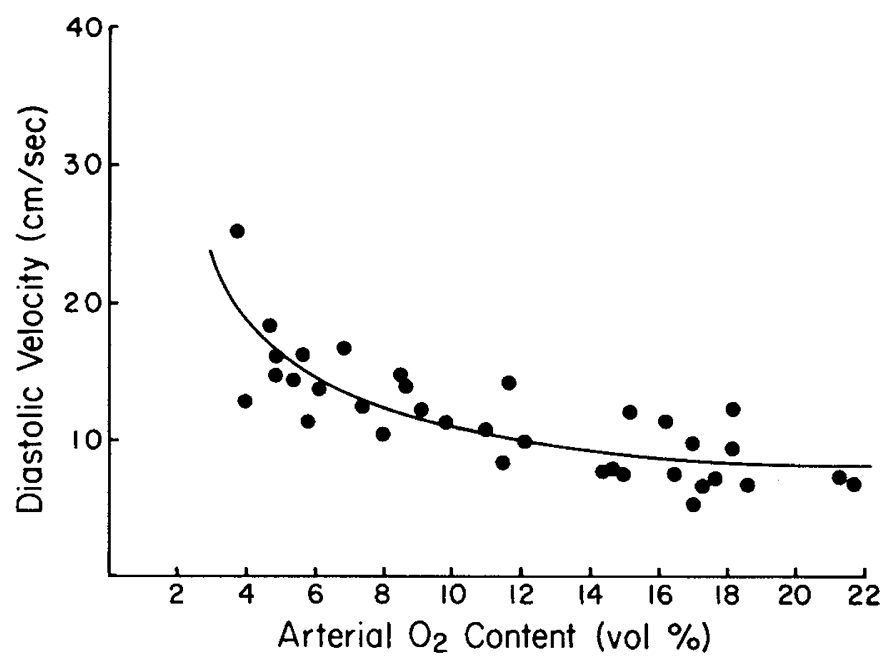

Fig. 2. Relationship of DV to arterial oxygen content in the lamb.

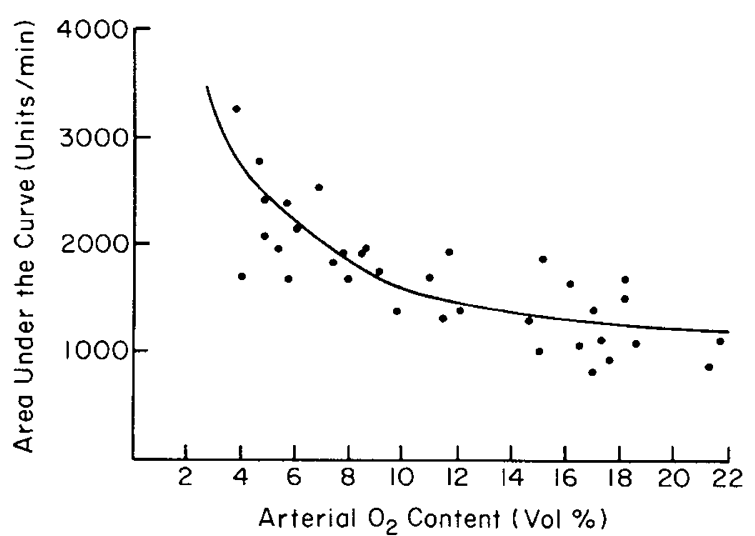

Fig. 3. Relationship of AUC to arterial oxygen content in the lamb.

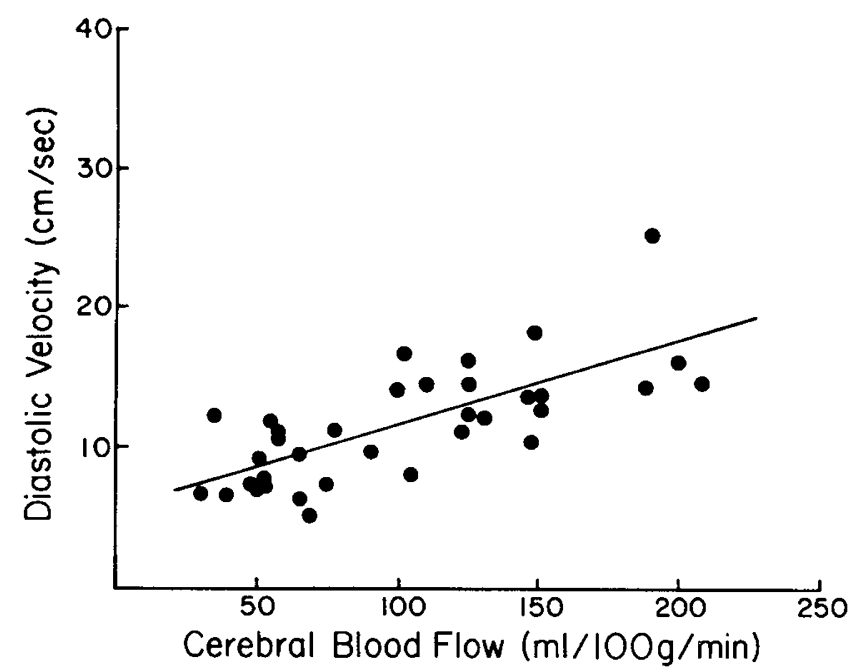

Fig. 4. Correlation between CBF measured with microspheres and DV measured with the Doppler.

\section{DISCUSSION}

The continuous wave Doppler technique uses a single transmitting and receiving crystal (20). The transmitter emits ultrasound of known frequency; a fraction of this ultrasound is reflected from moving $\mathrm{RBC}$ to reach the receiver crystal. The frequency of the reflected sound is shifted in proportion to the velocity of the RBC. This may be expressed mathematically as $\Delta \mathrm{f}=2 \mathrm{f}_{\mathrm{t}} \mathrm{V}(\cos \theta) / \mathrm{C}$, where $\Delta \mathrm{f}$ is the frequency shift of sound reflected by $R B C, f_{i}$ is the transmitting frequency, $V$ is velocity

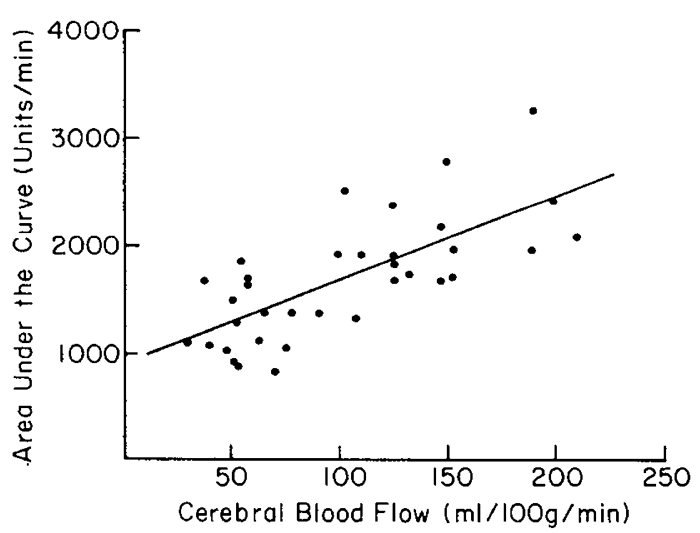

Fig. 5. Correlation between CBF measured with microspheres and AUC measured with the Doppler.

of the RBC, $\theta$ is the angle of incident sound beam with the blood vessel, and $C$ is the velocity of sound in the tissue. Since $f_{t}$ and $C$ are constants, if $\theta$ is held constant $\Delta f$ will be proportional to $V$. In fact, $\Delta f$ and $V$ have been shown to bear a close linear relationship in an in vitro model where $\theta$ was fixed (19). However, a shift as small as $4^{\circ}$ to either side of the optimal angle produces a $10 \%$ error in the determination (19).

As a result of the critical importance of the probe angle to reliable data, the PI is attractive because it minimizes errors in probe placement. However, there are critical limitations to the application of the PI to the human neonate. Not the least is that it was originally employed to assess obstruction in the carotid arteries of adults (14). Its relation to CVR was based on the assumption that a change in resistance changes diastolic flow velocity more than systolic velocity. Our data in the neonatal lamb do not support that contention. Both PSV and DV increased considerably during hypoxia. Similar results were also obtained during hypercapnia in neonatal pigs (8) and puppies (4). The PI cannot accurately reflect these large changes because PSV and DV changed together. This probably can explain why PI did not correlate with CBF in neonatal pigs, increased rather than decreased with hypercapnia in puppies, and demonstrated the poorest correlation with CBF during hypoxia in neonatal lambs. This could also be one explanation for inconsistencies in the clinical literature regarding PI $(1,12,13)$.

On the other hand, under strictly controlled circumstances with a constant probe angle, the actual velocity measurements are more useful in assessing changes in CBF in our neonatal lambs during hypoxia as well as in the studies of Batton et al. (4) and Hansen et al. (8) during hypercapnia. Including our current study, the Doppler technique has been shown to indicate actual changes in $\mathrm{CBF}$ under two different physiologic circumstances using three species. These data are also consistent with the data of Risberg and Smith (15) in human adults showing that carotid end diastolic velocity correlated with hemispheric blood flow measured with Xenon.

Although changes in the various velocity parameters (PSV, $\mathrm{DV}, \mathrm{AUC}$ ) correlate well with changes in $\mathrm{CBF}$ and are reasonable qualitative measures of changes in $\mathrm{CBF}$, Doppler flowmeters measure only velocity. To the extent that the cross-sectional area of the vessel changes, velocity is an imprecise indicator of total flow $(20,21)$. There is evidence in the literature that crosssectional area of cerebral arteries is not constant. Both large and small cerebral arteries have been shown to dilate with hypoxia and hypercapnia and constrict with hypocapnia $(7,9)$. Our data support the conclusion that the diameter of the ACA increases with hypoxia. In examining Figure 2 , it can be seen that as $\mathrm{CBF}$ increases from $100-200 \mathrm{ml} \cdot 100 \mathrm{~g}^{-1} \cdot \min ^{-1}$ (a $100 \%$ increase), DV increases from $11.5-17.5 \mathrm{~cm} \cdot \mathrm{s}^{-1}$ (a $52 \%$ increase). Similar calculations for PSV and AUC indicate that the change in these velocity parameters predict 41 and $45 \%$ of the change in CBF, respectively. This issue can also be examined utilizing the param- 
eter cerebral oxygen delivery $\left(\mathrm{OD}=\mathrm{CBF} \cdot \mathrm{CAO}_{2}\right)$. It has been previously demonstrated in the neonatal lamb that $\mathrm{OD}$ remains constant over a wide range of $\mathrm{CAO}_{2}(11)$. Such is also the case in the current study when OD is calculated using CBF measured by radioactive microspheres. In contrast, when similar calculations are made with diastolic velocity rather than $\mathrm{CBF}(\mathrm{OD}=$ DV. $\mathrm{CAO}_{2}$ ), oxygen delivery decreases as $\mathrm{CAO}_{2}$ decreases $(\mathrm{OD}=$ $\left.0.48 \mathrm{CAO}_{2}+6.15, \mathrm{r}=0.70, p<0.001\right)$. This is consistent with an underestimation of flow in high flow states by velocity determinations because changes in vessel diameter are not taken into account. This limited sensitivity of the technique combined with experimental error (Figs. 4 and 5) leads to a relatively poor quantitative prediction of CBF. Therefore, even in the best of circumstances, with probe angle constant in an immobile subject, measurement of blood velocity is not a good quantitative indicator of changes in CBF. With these limitations in mind however, measurement of the actual velocity parameters (PSV, DV, AUC) rather than $P I$ can provide valuable qualitative information about changes in $\mathrm{CBF}$ in the human neonate.

Acknowledgments. We thank Ms. Marguerite Lobb, Mrs. Patricia Williams, and Mrs. Karen Lingerman for secretarial assistance and Debra Limback for technical assistance.

\section{REFERENCES}

1. Bada HS, Hajjar W, Chua C, Sumner DS 1979 Noninvasive diagnosis of neonatal asphyxia and intraventricular hemorrhage by Doppler ultrasound. J Pediatr 95:775

2. Bada HS, Korones SB, Magill HL 1982 Specificity, sensitivity, and predictive value of Doppler flow studies in intraventricular hemorrhage. In: Syllabus of the Second Special Ross Laboratories Conference on Perinatal Intracranial Hemorrhage. Washington, D.C., pp 427-442

3. Bada HS, Miller JE, Menke JA, Menton TG, Bashiru M, Binstadt D, Sumner DS, Khanna NN 1982 Intracranial pressure and cerebral arterial pulsatile flow measurements in neonatal intraventricular hemorrhage. $J$ Pediatr 100:291

4. Batton DG, Hellman J, Hernandez MJ, Maisels MJ 1983 Regional cerebral blood flow, cerebral blood velocity, and pulsatility index in newborn dogs. Pediatr Res 17:908
5. Bejar R, Merritt TA, Coen RW, Mannino F, Gluck L 1982 Pulsatility index, patent ductus arteriosus, and brain damage. Pediatrics 69:818

6. Bejar R, Merritt TA, Coen RW, Mannino F, Gluck L 1983 Doppler debate continued. Pediatrics 71:471

7. Busija DW, Heistad DD, Marcus ML 1981 Continuous measurement of cerebral blood flow in anesthetized cats and dogs. Am J Physiol 241(Heart Circ Physiol 10):H228

8. Hansen NB, Stonestreet BS, Rosenkrantz TS, Oh W 1983 Validity of Doppler measurements of anterior cerebral artery blood flow velocity: correlation with brain blood flow in piglets. Pediatrics 72:526

9. Heistad DD, Marcus ML, Abboud FM 1978 Role of large arteries in regulation of cerebral blood flow in dogs. J Clin Invest 62:761

10. Heymann MA, Payne BD, Hoffman JIE, Rudolph AM 1979 Blood flow measurements with radionuclide-labeled particles. Prog Cardiovasc Dis 20:55

11. Jones MD Jr, Traystman RJ, Simmons MA, Molteni RA 1981 The effects of changes in arterial $\mathrm{O}_{2}$ content on cerebral blood flow in the lamb. Am J Physiol 240(Heart Circ Physiol 9):H209

12. Lipman B, Brazy JE 1983 Cerebral blood flow velocity in intraventricular hemorrhage. J Pediatr 102:324

13. Perlman JM, Volpe JJ 1982 Cerebral blood flow velocity in relation to intraventricular hemorrhage in the premature newborn infant. $J$ Pediatr 100:956

14. Planiol $T$, Pourcelot L 1974 Doppler effect study of the carotid circulation. In: deViegletz M, White DN, McCready VR (eds) Proceedings of the Second World Congress on Ultrasonics in Medicine. Exerpta Medica, Amsterdam, pp 104-111

15. Risberg J, Smith P 1980 Prediction of hemispheric blood flow from carotid velocity measurements: a study with the Doppler and ${ }^{133} \mathrm{Xe}$ inhalation techniques. Stroke 11:399

16. Rosenberg AA, Jones MD Jr, Traystman RJ, Simmons MA, Molteni RA 1982 Response of cerebral blood flow to changes in $\mathrm{PCO}_{2}$ in fetal, newborn, and adult sheep. Am J Physiol 242(Heart Circ Physiol 11):H862

17. Rosenkrantz TS, Oh W 1982 Cerebral blood flow velocity in infants with polycythemia and hyperviscosity: effects of partial exchange transfusion with Plasmanate. J Pediatr 101:94

18. Rosenkrantz T, Oh W 1982 Reduction of cerebral blood flow (CBF) in low birthweight (LBW) infants after aminophylline administration. Pediatr Res 16:306A

19. Shoor PM, Fronek A, Bernstein EF 1979 Quantitative transcutaneous arterial velocity measurements with Doppler flowmeters. Arch Surg 114:922

20. Strandness DE Jr 1982 Doppler ultrasonic techniques in vascular disease. In: Bernstein EF (ed) Noninvasive Diagnostic Technique in Vascular Disease. CV Mosby Co, St Louis, MO, pp 11-22

21. Uematsu S 1981 Determination of volume of arterial blood flow by an ultrasonic device. J Clin Ultrasound 9:209

22. Wallenstein S, Zucker CL, and Fleiss JL 1980 Some statistical methods useful in circulation research. Circ Res 47:1 